\title{
Impact of EU flavoured tobacco ban on waterpipe smoking
}

\author{
Mohammed Jawad honorary clinical research fellow, Christopher Millett reader in public health
}

Department of Primary Care and Public Health, Imperial College London, London W6 8RP, UK

We welcome the European Parliament's decision to ban flavoured tobacco, among other measures, in a bid to curb smoking in young people. ${ }^{1}$ Importantly, however, this ban applies to cigarettes and roll-your-own tobacco only-disappointingly, waterpipe tobacco is omitted. Waterpipe smoking is an increasingly popular and equally harmful form of tobacco use among young people in Europe,$^{2}$ and the tobacco used is almost exclusively flavoured. Waterpipes are typically smoked socially in bars or cafes, and England has witnessed a paradoxical $210 \%$ increase in such premises since the 2007 smoke-free law was introduced ${ }^{3}$ - London alone has around $400 .^{4}$

The unique appeal of waterpipe tobacco is its flavour, which includes a diverse range of fruits laced in molasses and is important in attracting new smokers. The decision not to include waterpipe smoking in this ban could greatly undermine tobacco control efforts, especially as targeting waterpipe smokers may reduce cigarette consumption in some settings. ${ }^{5}$

Where waterpipe smoking is not exempt from generic tobacco legislation, we seldom see guidance for the practical application of law to the waterpipe industry. For example, EU and UK legislation does not describe how health warning label requirements can be applied to the awkwardly sized waterpipe apparatus, which might be considered equivalent to a cigarette pack. As a result, these aspects of law are generally poorly enforced or not enforced at all. ${ }^{5}$

In contrast, a comprehensive EU ban on flavoured tobacco is a potential game changer for the waterpipe tobacco industry, as it effectively means a ban on waterpipe smoking where flavoured tobacco is used. We therefore call on legislative bodies to regulate waterpipe smoking on a par with cigarettes.

Competing interests: None declared.

Watson R. EU brings in new tobacco rules to deter young smokers. BMJ 2014;348:g1895 (3 March.)

2 Jawad M, Wilson A, Lee JT, Jawad S, Hamilton FL, Millett C. Prevalence and predictors of water pipe and cigarette smoking among secondary school students in London. Nicotine Tob Res 2013;15:2069-75.

3 British Heart Foundation. Rise in "shisha bars" prompts warning on dangers of waterpipe smoking. 2012. www.bhf.org.uk/default.aspx?page $=14417$.

4 Jawad M. Legislation enforcement of the waterpipe tobacco industry: a qualitative analysis of the London experience. Nicotine Tob Res 2014; published online 18 Mar.

5 Jawad M, Lee JT, Millett C. The relationship between waterpipe and cigarette smoking in low and middle income countries: cross-sectional analysis of the global adult tobacco survey. PLoS One 2014;9:e93097. 